\title{
Impacto de estratégia para a prevenção de diarreia entre crianças do ambulatório de uma faculdade de Belém-PA
}

\author{
Impact of a strategy to prevent diarrhea among children at an oupatient clinic in a college \\ in Belém-PA
}

\author{
Impacto de una estratégia para prevenir la diarrea entre los niños en uma clínica \\ ambulatoria em una universidad em Belém-PA
}

Rafaela Antônio de Bastos Ribeiro ${ }^{1 *}$, Camila Araujo Oliveira², Tellyson Araujo Furtado, Artur dos Santos Soares ${ }^{1}$, Thaís Vieira Tangerino ${ }^{1}$, Lays Vieira Cláudio Tangerino ${ }^{1}$, Rafaela Caroline Amador Ferreira $^{2}$, Sheila Mara Dias ${ }^{1}$.

\begin{abstract}
RESUMO
Objetivo: Intervir no conhecimento sobre hábitos de higiene de pais/responsáveis pelas crianças no Ambulatório de Pediatria de uma faculdade de Belém-PA. Métodos: Projeto aprovado pelo Comitê de Ética em Pesquisa para avaliar o conhecimento de pais/responsáveis de crianças cadastradas em um ambulatório de pediatria de uma faculdade de Belém/PA sobre higiene de mãos e alimentos que possa diminuir o risco de contaminação e diarreia em crianças por meio de um questionário estruturado pelos autores passado antes e após uma palestra de educação em saúde sobre o tema. Resultados: A maioria das crianças estavam entre sete e dez anos, residiam na zona urbana de Belém e possuíam sistema de esgoto público para os dejetos da residência. Em torno de $12 \%$ dos pais não deixavam alimentos em água com hipoclorito de sódio sendo esta taxa que houve mudança para $75 \%$ após a educação em saúde. Conclusão: $O$ conhecimento produzido por este estudo contribuiu para o entendimento da diversidade dos fatores associados à ocorrência de diarreia ao identificar condições associáveis brevemente investigadas, como o manejo e higienização dos alimentos, ingesta da água e lavagem adequada das mãos.
\end{abstract}

Palavras-Chave: Diarreia, Epidemiologia, Criança.

\begin{abstract}
Objective: To intervene in the knowledge about hygiene habits of parents / guardians of children in the Pediatric Clinic of a college in Belém-PA. Methods: Project approved by the Research Ethics Committee to assess the knowledge of parents / guardians of children registered in a pediatric outpatient clinic at a college in Belém / PA on hand and food hygiene that can reduce the risk of contamination and diarrhea in children through a questionnaire structured by the authors before and after a health education lecture on the topic. Results: Most of the children were between seven and ten years old, lived in the urban area of Belém and had a public sewage system for the residues of the residence. Around $12 \%$ of parents did not leave food in water with sodium hypochlorite, this rate having changed to $75 \%$ after health education. Conclusion: The knowledge produced by this study contributed to the understanding of the diversity of factors associated with the occurrence of diarrhea by identifying associated conditions briefly investigated, such as food handling and hygiene, water intake and proper hand washing.
\end{abstract}

Key words: Diarrhea, Epidemiology, Child.

\section{RESUMEN}

Objetivo: Intervenir en el conocimiento sobre los hábitos de higiene de los padres / tutores de los niños en la Clínica Pediátrica de una universidad en Belém-PA. Métodos: Proyecto aprobado por el Comité de Ética en

${ }^{1}$ Centro Universitário Metropolitano da Amazônia (UNIFAMAZ), Belém - PA. *E-mail: rafaelabastos_16@hotmail.com

2 Universidade Federal do Pará (UFPA), Belém - PA.

SUBMETIDO EM: 1/2020

ACEITO EM: 2/2020

PUBLICADO EM: 5/2020

REAS/EJCH | Vol.Sup.n.48 | e3004 | DOI: https://doi.org/10.25248/reas.e3004.2020 Página 1 de 9 
Investigación para evaluar el conocimiento de los padres / tutores de niños registrados en una clínica pediátrica ambulatoria en una universidad en Belém / PA sobre higiene de manos y alimentos que puede reducir el riesgo de contaminación y diarrea en niños a través de un cuestionario estructurado por los autores antes y después de una conferencia sobre educación en salud sobre el tema. Resultados: la mayoría de los niños tenían entre siete y diez años, vivían en el área urbana de Belém y tenían un sistema de alcantarillado público para los residuos de la residencia. Alrededor del 12\% de los padres no dejaron alimentos en el agua con hipoclorito de sodio, esta tasa cambió al $75 \%$ después de la educación sanitaria. Conclusión: El conocimiento producido por este estudio contribuyó a la comprensión de la diversidad de factores asociados con la aparición de diarrea mediante la identificación de las condiciones asociadas que se investigaron brevemente, como la manipulación e higiene de los alimentos, la ingesta de agua y el lavado de manos adecuado.

Palabras clave: Diarrea, Epidemiologia, Niño.

\section{INTRODUÇÃO}

A diarreia aguda (DA) é uma das doenças mais frequentes na sociedade, sendo o agente etiológico rotavírus um dos principais e mais importantes causadores desta patologia e portanto óbitos em crianças menores de cinco anos no mundo. A DA possui uma duração média de sete dias de tempo, contudo casos onde se estende para mais de quatorze dias, denomina-se diarreia crônica que pode ser causada por bactérias, vírus, parasitas, perda excessiva de água e/ou eletrólitos. No entanto, a DC já apresenta como principais causas as doenças inflamatórias intestinais, síndrome do intestino irritável, síndrome de má absorção sendo um exemplo comum a intolerância a lactose (BRASIL, 2015).

A DA apresenta como complicações: perda excessiva de eletrólitos e água via retal, acarretando desidratação; diminuição da imunoglobulina A secretora entérica; contaminação bacteriana do intestino delgado; aumento da permeabilidade; translocação bacteriana; sepse; intolerância à proteína; lesão de microvilosidades; diminuição da enzima lactase e intolerância à lactose; aumento do catabolismo, diminuição da ingestão de alimentos (anorexia-vômitos) e desnutrição aguda (BRASIL, 2015).

Considerando que a transmissão do rotavírus ocorre basicamente pela via fecal- oral, contaminação de alimentos, água e objetos, a introdução de medidas de prevenção e controle é necessária, tanto em âmbito hospitalar, quanto doméstico. Precisa ser destacado que essa doença pode ser evitada com o cumprimento de costumes higiênicos como lavar as mãos. Alguns estudos indicam que as mães são, em sua maioria, responsáveis de conduzir o contexto de diarreia infantil (CARVALHO T, et al., 2014).

Para que uma pessoa possa desenvolver hábitos saudáveis, é necessário que possua auto eficácia para conseguir manter na rotina diária, além do conhecimento. Dessa forma, a mãe necessita desse conhecimento a fim de prevenir a diarreia sendo aliada na construção de saúde do filho.

É preocupante o elevado número de casos de diarreia em crianças até os 12 anos de idade, principalmente em bairros da periferia dos centros urbanos, constituindo um grave problema de saúde pública. A partir dessa realidade, entendendo que a doença afeta consideravelmente grande parcela da população infantil, podendo acarretar morbidades responsáveis pelo desequilíbrio das condições de saúde, afetando o desenvolvimento psicomotor e cognitivo da criança, reduzir tais acometimentos é de primordial importância (BRASIL, 2017).

Assim, diante dessas circunstâncias, tornou-se importante conhecer o grau de conhecimentos sobre hábitos de higiene e manipulação de alimentos dos pais/responsáveis pelas crianças atendidas no Ambulatório de Pediatria para a realizações de medidas de intervenção, que possam fornecer e/ou aprimorar conhecimentos, afim de prevenir os casos de diarreia aguda infantil. Dessa forma, foram ministradas palestras com entrega de folders de fácil entendimento, para que tivessem a consolidação dessas informações pelos indivíduos da pesquisa, que por sua vez poderão tornar-se multiplicadores dessas informações à população.

Logo, o objetivo do estudo é intervir no conhecimento sobre hábitos de higiene de pais/responsáveis pelas crianças no Ambulatório de Pediatria de uma faculdade de Belém-PA através de um questionário antes e após ação educativa educativa visando prevenção de diarreia. 


\section{MÉTODOS}

O presente estudo teve início após aprovação pelo Comitê de Ética em Pesquisa (CEP) da instituição sob CAAE: 02779718.2.0000.5701. Todos os sujeitos envolvidos foram consultados sobre sua participação na investigação, e esclarecidos com leitura do aceite da instituição, aceite do orientador, assinatura do Termo de Consentimento livre e esclarecido (TCLE), termo de compromisso dos pesquisadores responsáveis, de acordo com que preconiza a Resolução 466/12 do CNS/MS, o Código de Nuremberg e a declaração de Helsinque. Os participantes tiveram o direito de desistir da pesquisa em qualquer momento. Todos os envolvidos assinaram o TCLE A pesquisa foi realizada com os pais/responsáveis pelas crianças que se encontravam na fase Escolar (4-10 anos), de acordo com classificação da Sociedade Brasileira de Pediatria, cadastradas no Ambulatório de Pediatria de uma instituição no período de fevereiro de 2018 a fevereiro de 2019.

Através da busca ativa dos prontuários foram considerados elegíveis para a pesquisa, os pais/responsáveis pelas crianças na faixa etária de 4-10 anos, de ambos os sexos, cadastradas no Ambulatório de Pediatria no período de fevereiro de 2018 a fevereiro de 2019. Além disso, foram considerados para a presente pesquisa apenas os pais/responsáveis que aceitaram participar voluntariamente do projeto de intervenção, sendo submetidos a assinatura do TCLE.

Foram excluídos da pesquisa, os pais/responsáveis que na data da consulta registrada no prontuário a criança encontrou-se fora da faixa etária de 4-10 anos, os pais/responsáveis que se recusaram participar da pesquisa, os pais/responsáveis que não responderam os dois questionários de forma completa, os pais/responsáveis que não participaram da capacitação (minicurso) e os pais/responsáveis que não foi possível contata-los.

Na primeira etapa da pesquisa foram solicitados os prontuários de todas as crianças assistidas no Ambulatório de Pediatria do foram coletados os seguintes dados: data de nascimento, data da consulta e telefone dos responsáveis. Na etapa posterior foram contatados todos os pais/responsáveis pelas crianças por meio de busca ativa para participação do estudo e apresentação do TCLE.

$\mathrm{Na}$ terceira fase da pesquisa foi realizado um cronograma e programada uma agenda de atividades com medidas educacionais (palestra e folder). Na quarta etapa da pesquisa foi usado um questionário sociodemográfico (Questionário A) para os pais/responsáveis das crianças que consistiu em uma análise do perfil dos participantes em relação às seguintes variáveis: idade, escolaridade, procedência, condições de moradia, renda mensal, atividade laboral, tipo de alimentação, manipulação de alimentos e aleitamento materno. Por meio de um segundo questionário (Questionário B), foi avaliado se os pais/responsáveis pelas crianças apresentavam grau de informação adequado sobre hábitos de higiene para prevenção de diarreia, antes da capacitação (palestra e folder). Em caso de dificuldade de interpretação por parte do participante houve a confirmação da informação por parte do pesquisador e em caso de dificuldade visual o pesquisador fez a leitura do questionário.

Na quinta etapa da pesquisa após análise do questionário foi realizada uma capacitação (palestra e folder), por meio de palestra ministrada pelos pesquisadores para os pais e responsáveis das crianças, no Ambulatório de Pediatria, onde foi debatido sobre hábitos de higiene através de vídeos, folders e palestras que visaram mudança de hábitos e instruíram sobre técnicas de manipulação de alimentos e uso de água potável. Na última etapa da pesquisa foi repassado o Questionário B analisando a consolidação da informação repassada durante a capacitação.

Sendo universo amostral de 400 crianças cadastradas no Ambulatório de Pediatria foi encontrado a amostragem probabilística de 40 pais/responsáveis pelas crianças no período de fevereiro de 2018 até fevereiro de 2019 realizados no Ambulatório de Pediatria, na qual foram usados dois questionários próprios autoaplicáveis, onde foram abordadas perguntas pertinentes sobre características pessoais dos participantes, conhecimentos prévios e adquiridos após a ação educativa. Para análise dos dados foi calculada a média e a porcentagem de seus respectivos grupos. Os dados coletados foram inseridos em uma planilha do software Microsoft Excel $2018^{\circledR}$ e os resultados foram expostos por meio de gráficos e tabelas. 


\section{RESULTADOS}

Durante a avaliação da idade das crianças cadastradas no Ambulatório de Pediatria do Centro Universitário foi observado uma prevalência em crianças de 10 anos (20\%), 7 anos (20\%), 4 anos (12,5\%), 5 anos (12,5\%), 6 anos (12,5\%), 9 anos (12,5\%), 8 anos (10\%). Mediante a avaliação do sistema de esgoto da residência dos pais/responsáveis pelas crianças cadastradas no Ambulatório de Pediatria do Centro Universitário, notou-se uma maior prevalência com esgoto público (40\%), seguido de esgoto a céu aberto $(37,5 \%)$, diretamente no solo $(15 \%)$, outros $(7,5 \%)$, diretamente no rio $(0 \%)$. Durante a avaliação da zona, onde residem pais/responsáveis das crianças cadastradas no Ambulatório de Pediatria do Centro Universitário, observouse uma grande prevalência da população pesquisada residindo na zona urbana com $92,5 \%$ e na zona rural de $7,5 \%$.

$\mathrm{Na}$ avaliação do grau de escolaridade dos pais/responsáveis observou-se que $50 \%$ dos responsáveis tinham escolaridade até o ensino fundamental, $30 \%$ até ensino médio, $10 \%$ possuíam o ensino superior incompleto e $10 \%$ tinham ensino superior completo. Ao avaliar a atividade laboral dos pais/responsáveis pelas crianças observou- se que $75 \%$ possuem atividade laboral informal e $25 \%$ atividade laboral formal.

Ao avaliar conhecimento sobre o manuseio e higiene das frutas antes e após aplicação da palestra para os pais/responsáveis pelas crianças cadastradas no Ambulatório de Pediatria do Centro Universitário, observouse que houve uma consolidação do conhecimento após a palestra onde 75\% optaram por deixar de molho em água com hipoclorito e passaram a não lavar somente com água corrente (Gráfico 1).

Gráfico 1 - O conhecimento sobre o manuseio e higiene das frutas antes e após aplicação da palestra para os pais/responsáveis pelas crianças cadastradas no Ambulatório de Pediatria do Centro Universitário. Belém - PA, 2019.

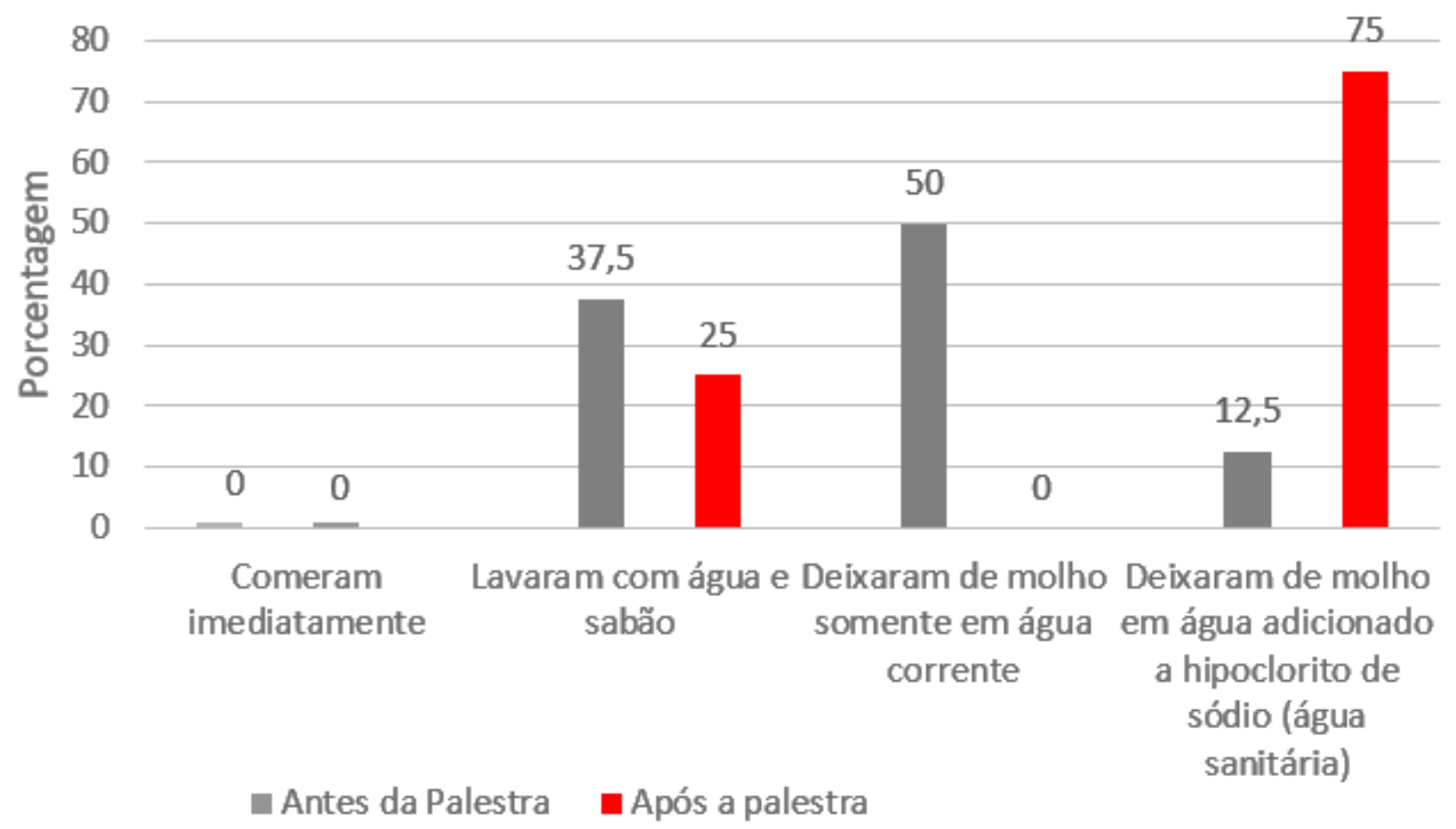

Fonte: Ribeiro RAB, et al., 2020.

Ao avaliar conhecimento sobre o manuseio e higiene de verduras e legumes antes e após aplicação da palestra para os pais/responsáveis pelas crianças cadastradas no Ambulatório de Pediatria do Centro Universitário, observou- se que houve uma consolidação do conhecimento após a palestra, onde $90 \%$ optaram por deixar de molho em água com hipoclorito e passaram a não lavar somente com água corrente (Gráfico 2). 
Gráfico 2 - O conhecimento sobre o manuseio e higiene de legumes e verduras antes e após aplicação da palestra para os pais/responsáveis pelas crianças cadastradas no Ambulatório de Pediatria do Centro Universitário. Belém - PA, 2019.

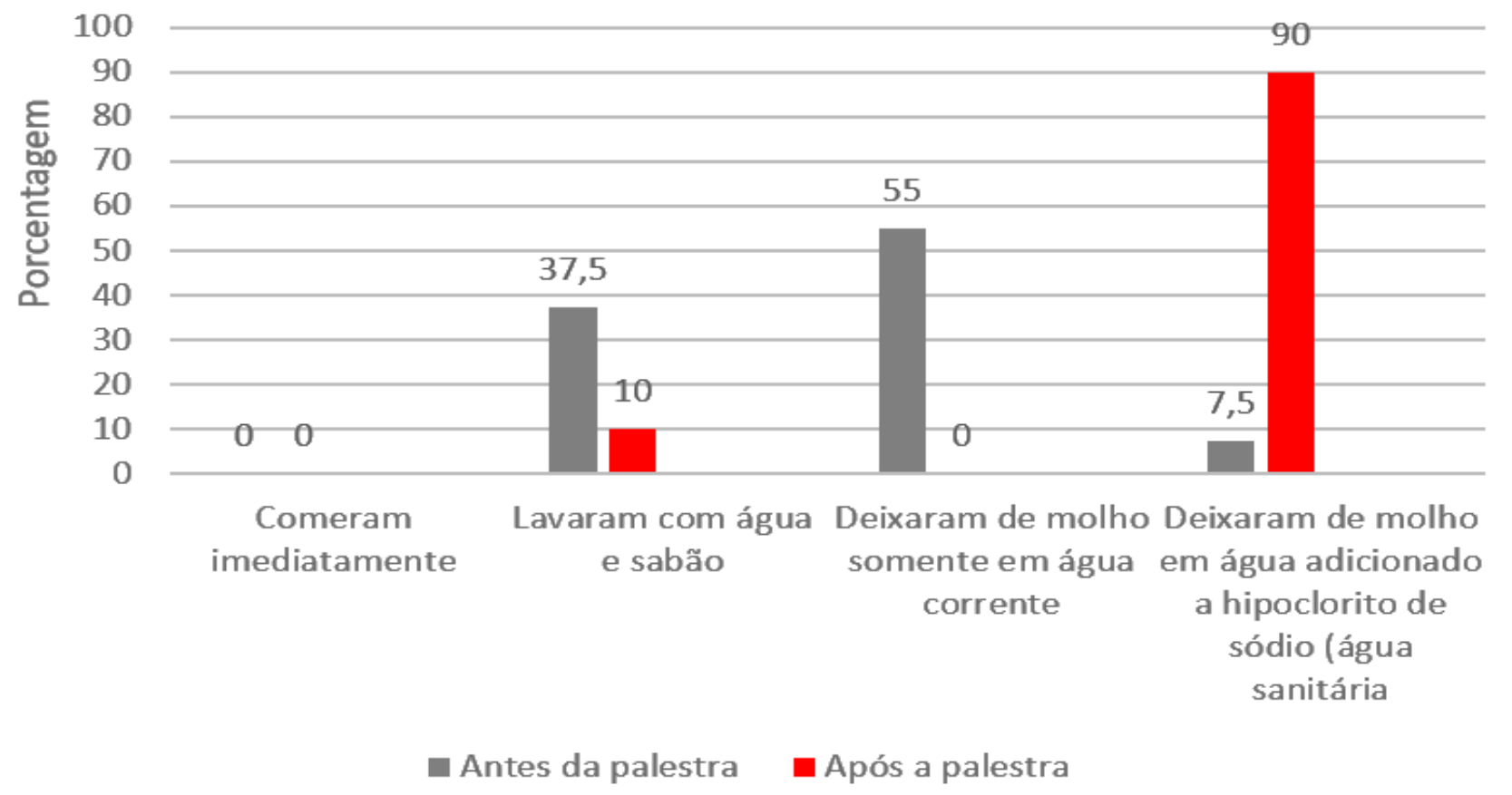

Fonte: Ribeiro RAB, et al., 2020.

$\mathrm{Na}$ avaliação do conhecimento sobre a utilização da água antes e após a palestra dos pais/responsáveis pelas crianças cadastradas no Ambulatório de Pediatria do Centro Universitário observou-se que houve uma melhora na conscientização, principalmente de pais/responsáveis que residiam em zona rural, relataram que faziam uso da água de poço (5\%), e que após a aplicação da palestra mudaram seu posicionamento e entenderam a importância da ingestão de água fervida/potável (Gráfico 3).

Gráfico 3 - O conhecimento sobre a utilização da água antes e após a palestra dos pais/responsáveis pelas crianças cadastradas no Ambulatório de Pediatria do Centro Universitário. Belém - PA, 2019.

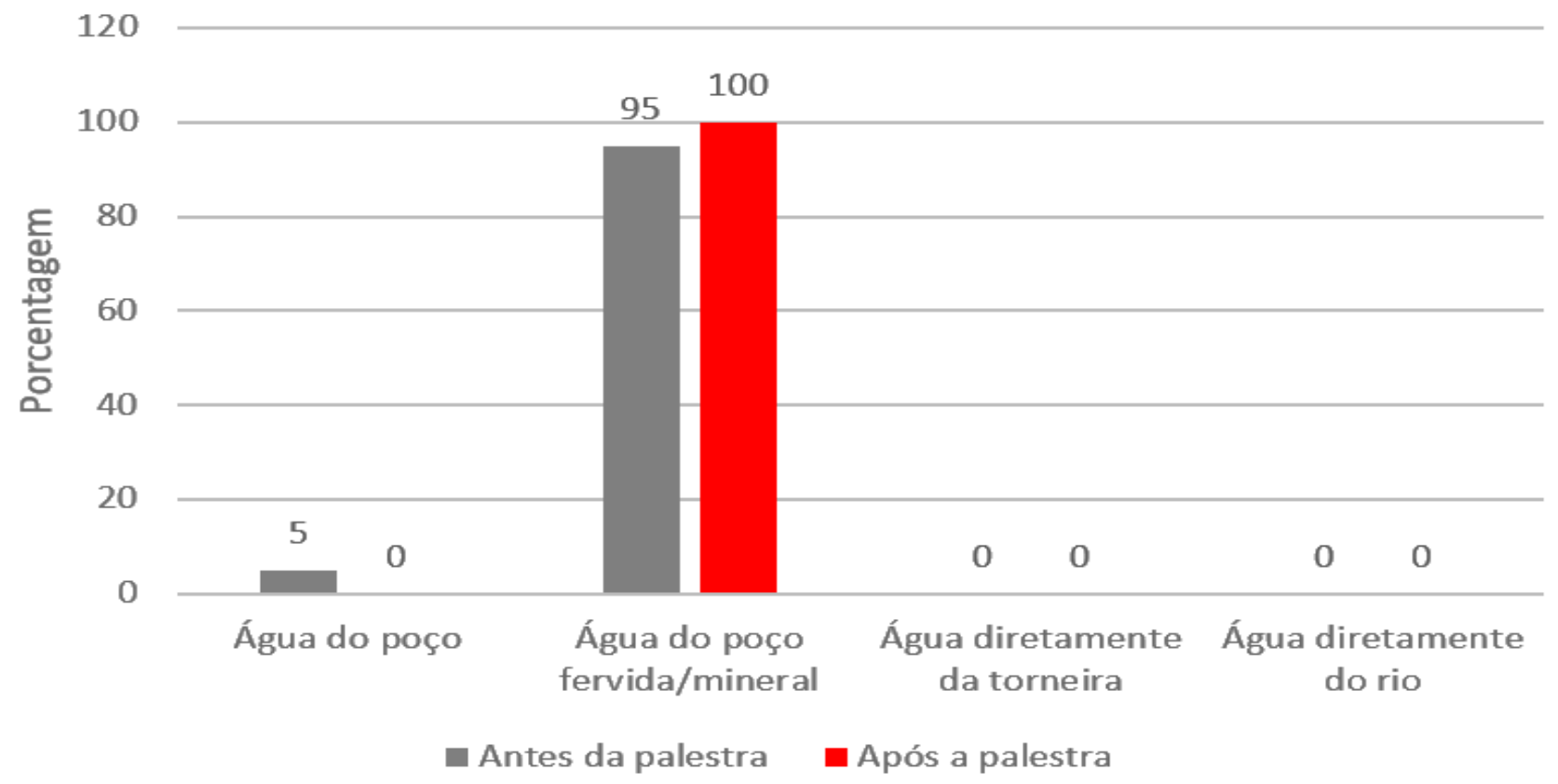

Fonte: Ribeiro RAB, et al., 2020. 
O conhecimento sobre hábitos de higiene antes e após aplicação da palestra aos pais/responsáveis pelas crianças cadastradas no Ambulatório de Pediatria do Centro Universitário observou-se que a maioria tinha conhecimento da importância de manter as unhas cortadas (Gráfico 4).

Gráfico 4 - O conhecimento sobre hábitos de higiene (unhas cortadas) antes e após aplicação do minicurso dos pais/responsáveis pelas crianças cadastradas no Ambulatório de Pediatria do Centro Universitário. Belém - PA, 2019.

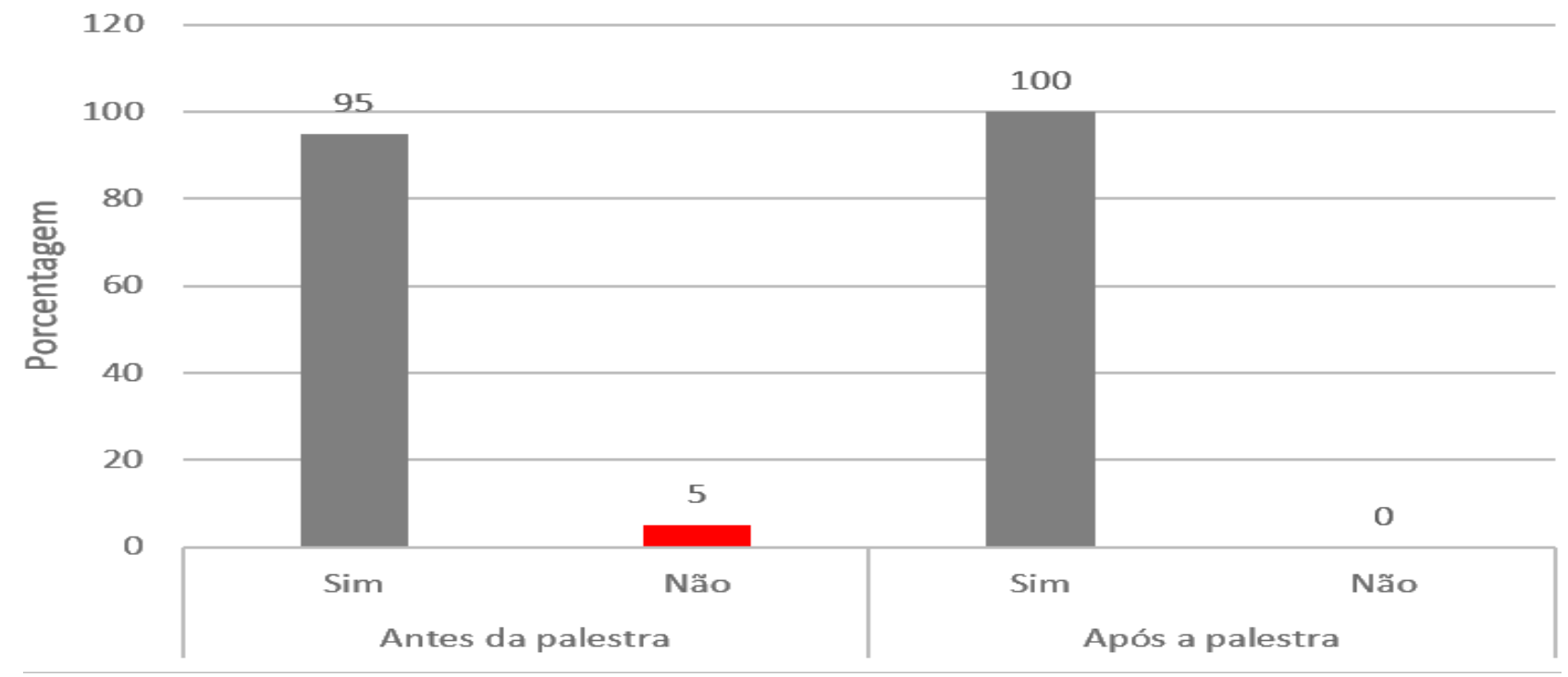

Fonte: Ribeiro RAB, et al., 2020.

O conhecimento sobre hábitos de lavar as mãos antes e após aplicação da palestra aos pais/responsáveis pelas crianças cadastradas no Ambulatório de Pediatria do Centro Universitário, observou-se que todos tinham conhecimento da importância de manter a higiene das mãos com água e sabão, antes da alimentação. O conhecimento sobre hábitos de higiene das mãos antes e após a aplicação, antes da palestra foi percebido que 2,5 assinalaram que bastava lavar somente com água e 97,5 com água e sabão. Após a aplicação da educação em saúde, todos assinalaram que precisava lavar as mãos com água e sabão (Gráfico 5).

Gráfico 5 - O conhecimento sobre hábitos de higiene das mãos antes e após aplicação da palestra aos pais/responsáveis pelas crianças cadastradas no Ambulatório de Pediatria do Centro Universitário. Belém PA, 2019.

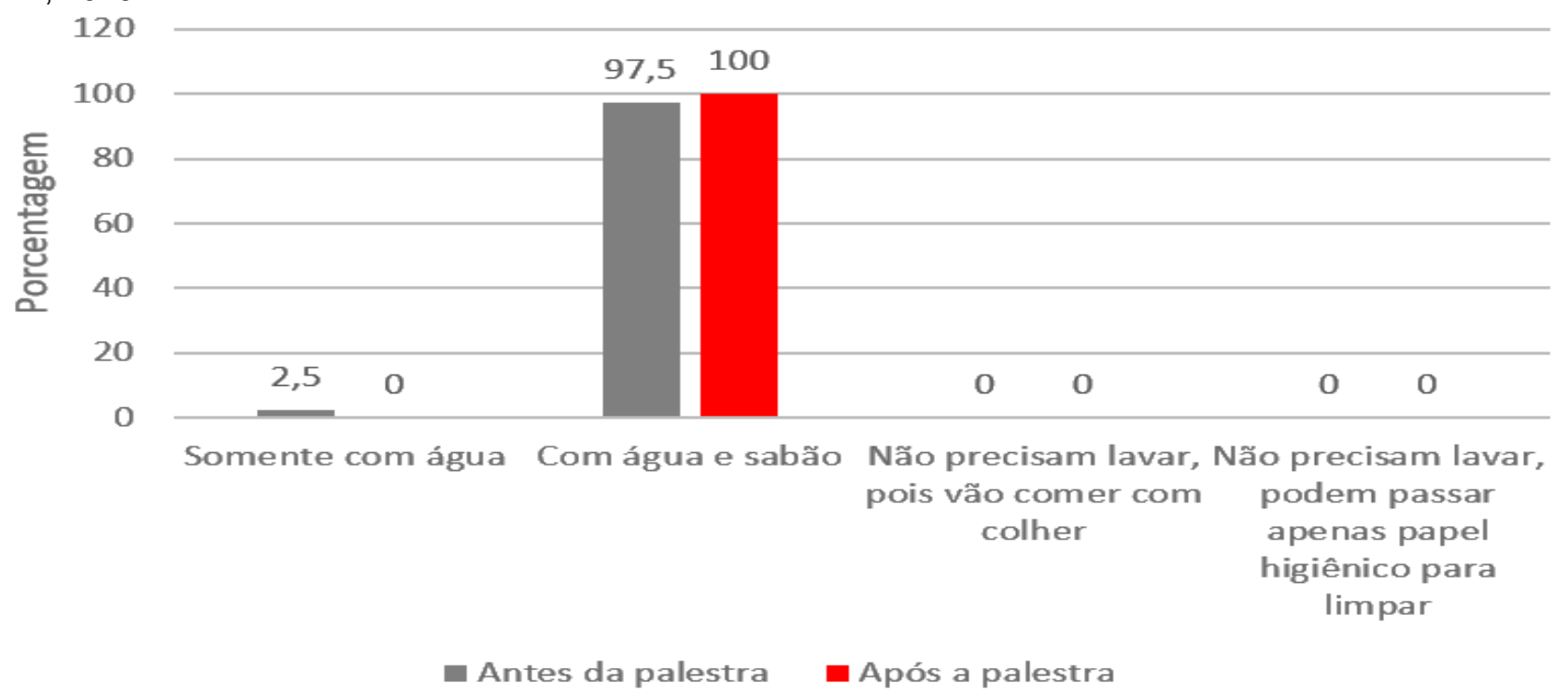

Fonte: Ribeiro RAB, et al., 2020. 


\section{DISCUSSÃO}

Por muitos lugares não terem acesso a rede de esgoto adequadamente, os problemas de saúde que necessitam de higiene aparecem em um contexto de possibilidade de veiculação de doenças relacionadas a excretas, cuja maioria gera como um dos sintomas, a diarreia. Sendo um importante foco de poluição, é um fator de risco para a saúde da população (PAZ MGA, et al., 2012; PEDRAZA DF, 2017). No ambulatório do Centro Universitário reflete a situação de grande parte das áreas urbanas das cidades do estado do Pará, onde $37,5 \%$ tem sistema de esgoto a céu aberto e $15 \%$ esgoto diretamente no solo. Tais condições geram uma degradação e perda ambiental em áreas de mananciais de abastecimento além de problemas de saúde para a população. (IMADAL K, et al., 2016).

As condições socioeconômicas e de escolaridade são relatadas na literatura como um fator de risco para a ocorrência da diarreia, onde a renda familiar é um fator determinante do nível de bem-estar social (IMADAL $\mathrm{K}$, et al., 2016; SABINO LMM, et al., 2018). Pode-se inferir que quanto maior valor e a estabilidade da renda familiar, mais adequado é o seu acesso à educação, à alimentação e à moradia estruturalmente completa, compreendendo cômodos como cozinha reservada ao preparo de alimentos, banheiro em seu interior, e saneamento, com abastecimento adequado de água, esgotamento sanitário e coleta regular de lixo (IMADAL $\mathrm{K}$, et al., 2016; VASCONCELOS MOJB, et al., 2018).

Neste trabalho, o questionário mostrou que $75 \%$ dos responsáveis tem atividade laboral informal e apenas $25 \%$ formal, desta forma a maioria vive em condição de renda não fixa e que depende de vários fatores relacionados à economia local. Já no quesito escolaridade, 50\% têm ensino fundamental completo, $30 \%$ ensino médio completo, $10 \%$ ensino superior incompleto, configurando assim a realidade encontrada principalmente nas populações urbanas do país (IMADAL K, et al., 2016).

O presente estudo mostrou que viver em grandes centros urbanos é fator de risco para diarreia aguda, onde $92,5 \%$ dos participantes moram na zona urbana e $7,5 \%$ na zona rural, fato que está relacionado ao crescimento urbano desordenado onde o saneamento básico não consegue acompanhar na mesma velocidade, de tal forma a deixar essas populações mais suscetíveis a condições precárias de esgoto. As doenças diarreicas ainda permanecem como uma das mais importantes causas de morbidade e mortalidade entre pré-escolares e escolares nos países em desenvolvimento (ESTEVAM LS, 2016). Segundo a Sociedade Brasileira de Pediatria, as causas de diarreia na criança são inúmeras, no entanto, as principais são divididas em grupos, como exemplo: 1) Infecciosas bacterianas: Salmonella, Shigella, Campylobacter, Yersinia, Escherichia coli; 2) Infecciosas virais: Rotavírus, Norovírus, Adenovírus; 3) Infecciosas por protozoários: ameba, Giárdia lamblia, Cryptosporidium16. Dessa forma, assegurar condições de higiene adequada é um fator determinante para diminuir os casos de diarreia nessas crianças (SANTOS AP, et al., 2018; BRASIL, 2019).

O cenário encontrado no Ambulatório da Faculdade, após aplicação do questionário demostra que há falta de conhecimento a respeito de condições de higiene, dessa forma parte das crianças na faixa etária de 4-10 anos, estão expostas a condições como lavagem incorreta de alimentos, ingesta inadequada de água, aumentando os riscos de desenvolver diarreia. Diante disso, após realização da palestra, os pais e responsáveis modificaram as respostas no segundo questionário demonstrando que adquiriram conhecimento necessário de noções básicas de higiene (AKBULUT EU, et al., 2018; BRASIL, 2019).

Segundo o Sistema Nacional de Informação sobre Saneamento, a capital paraense, Belém, permanece com um dos piores índices de saneamento básico entre as capitais do país: apenas 10\% da população tem acesso à rede de esgoto e distribuição de água encanada, enquanto a média nacional é de $57 \%$ de cobertura. Baseado nos resultados adquiridos foi possível comprovar que essa precariedade se faz presente em $37,5 \%$ da população analisada, sendo este um importante fator de risco para contrair diarreia, devido ao fato de que o consumo de água pública diminui a possibilidade de doenças diarreicas pelo padrão alto que exigem para distribuição e qualidade para consumo humano (BRASIL, 2019).

Outra variável relacionada ao saneamento básico é o consumo de água. Dos entrevistados, apenas $5 \%$ consumiam água diretamente do poço, após instrução da palestra, 100\% dos entrevistados optaram pelo 
consumo de água do poço fervida, ou consumo de água mineral. É importante realizar a preparação adequada da água para consumo, pois muitas vezes o abastecimento de água advém de fontes alternativas, que possuem qualidade duvidosa e que pode ser imprópria para consumo humano, contudo por problemas ambientais como a seca em diversos estados, muitas vezes, a família condiciona um reservatório próprio a guardar água de qualidade duvidosa que pode prejudicar a saúde humana (GUNTHER WMR, et al., 2012; MAMANI LR, et al., 2019).

De acordo com a Organização Mundial da Saúde, o simples ato de lavar as mãos reduz em até $40 \%$ o risco de contrair doenças como diarreia. Há várias situações em casa em que a higienização de mãos é obrigatória: antes, durante e depois do preparo de qualquer alimento; antes de tocar em qualquer coisa que vá à boca do bebê; antes e depois de pegar numa pessoa doente; após coçar ou assoar o nariz; antes e depois das refeições; após ir ao banheiro; antes e depois de tratar algum machucado ou ferimento; depois de trocar fraldas ou ajudar uma criança a se limpar; depois de tocar, alimentar ou limpar um animal; depois de manipular a comida ou objetos de seu gato ou cachorro e depois de tocar no lixo (BRANDY KG, et al., 2015; TABORDA RLM, et al., 2018).

Os resultados apresentados demonstram que esse conhecimento já está consolidado entre os pais e responsáveis das crianças atendidas no ambulatório de pediatria do Centro Universitário, haja vista que antes da aplicação da palestra, $100 \%$ dos entrevistados sabiam da importância da higienização das mãos como medida de prevenção dos casos de diarreia (BRASIL, 2015).

De acordo com a Organização Mundial de Saúde, as doenças transmitidas por alimentos são grande preocupação de saúde pública, e a cada ano, causam o adoecimento de 1 a cada 10 pessoas (BRASIL, 2019). Quando hortifrutis são mal lavados e consumidos crus, podem transmitir bactérias, como as Salmonella, Shigellas e Escherichia coli (E. coli), que provocam diarreias em diferentes intensidades (BRASIL, 2015; OLIVEIRA PD, et al., 2019). A melhor maneira de prevenir doenças por alimentos envolve, dentre outras práticas, a seleção de alimentos frescos de boa aparência e a limpeza e desinfecção de frutas, legumes e verduras com lavagem em água corrente e imersão em solução preparada com $10 \mathrm{ml}$ (1 colher de sopa) de hipoclorito de sódio a 2,5\% para cada litro de água tratada (BRASIL, 2019; MACEDO JCB, et al., 2019), deixando de molho de 15 a 20 minutos e lavando abundantemente depois.

De acordo com os resultados obtidos dos questionários aplicados, percebe-se que antes da palestra, 55\% dos pais deixavam os legumes e verduras de molho somente em água corrente. Entretanto, após a exposição na palestra sobre a melhor desinfecção de alimentos em água clorada, $90 \%$ dos pais entenderam e preencheram o questionário com a resposta correta e somente $10 \%$ ainda permaneceram na alternativa de lavagem dos alimentos somente com água e sabão. Através desta pesquisa, entende-se que o conhecimento sobre a melhor prática de desinfecção dos alimentos era debilitado, após a palestra o conhecimento e as informações sedimentaram- se e os pais conseguiram entender a melhor prática para uma boa higiene e evitar a doença diarreica em suas crianças (PONTUA JPS, et al., 2006; BRASIL, 2019).

\section{CONCLUSÃO}

O conhecimento produzido por este estudo contribuiu para o entendimento da diversidade dos fatores associados à ocorrência de diarreia ao identificar condições associáveis brevemente investigadas, como o manejo e higienização dos alimentos, ingesta da água e lavagem adequada das mãos. As medidas imediatas foram realizadas através de palestra e folder fornecendo orientações para população sobre aspectos importantes relacionados a ocorrência de diarreia, tais como o cuidado domiciliar da água para consumo, conservação adequada dos alimentos e práticas de higiene.

\section{REFERÊNCIAS}

1. AKBULUT UE, et al. Duodenal pathologies in children: a single-center experience. J. Pediatr. 2018; 94(3).

2. BRASIL. Secretaria de Estado da Saúde. Manual do acompanhamento da criança. 2015; 13:12. 
3. BRASIL. Sociedade Brasileira de Pediatria. Departamento Científico de Gastroenterologia. Guia Prático de Atualização. 2017; 09(46): 23.

4. BRASIL. Ministério da Saúde. Doenças transmitidas por alimentos: causas, sintomas, tratamento e prevenção, 2019.

5. BRASIL. Frutas e legumes sem sanitização e carne mal passada podem transmitir doenças graves. Hospital Sírio- Libanês, 2015.

6. BRANDY KG, et al. Acute diarrhea: evidence-based management. J Pediatr (Rio J). 2015; 91: S36-43.

7. CARVALHO T, et al. Conhecimento sobre gastroenterite viral pelos profissionais de saúde de um hospital materno-infantil de referência no Estado do Pará. Rev Pan-Amaz Saude, 2014; 5(3).

8. ESTEVAM LS. Diarreia aguda: um olhar para a prevenção e educação em saúde de escolares da comunidade canafistula do município de Girau de Ponciano- Alagoas. 2016.

9. GUNTHER WMR, et al. Prevalência de diarreia em crianças e condições de saneamento e moradia em áreas periurbanas de Guarulhos, SP. Rev Bras Epidemiol., 2012; 15(1): 188-97.

10. IMADAL K, et al. Fatores socioeconômicos, higiênicos e de saneamento na redução de diarreia na Amazônia: Brasil, Departamento de Engenharia Sanitária e Ambiental. Escola de Engenharia. Universidade Federal de Minas Gerais. Belo Horizonte, Rev Saúde Pública. 2016; 50: 77.

11. MACEDO JCB, et al. Factors associated with pneumonia and diarrhea in children and quality of primary health care. Texto contexto - enferm., Florianópolis. 2019; 28: e20180225.

12. MAMANI LR, et al. Estrategias para disminuir diarreas parasitosis y anemia en menores de cinco años zona altoandina Perú. Horiz. sanitario, Villahermosa, 2019; 18(3): 307-317.

13. OLIVEIRA PD, et al. Day care attendance during the first 12 months of life and occurrence of infectious morbidities and symptoms. J. Pediatr. 2019; 95(6): 657-666.

14. PAZ MGA, et al. Prevalência de diarreia em crianças e condições de saneamento e moradia em áreas periurbanas de Guarulhos, SP: Brasil, Rev Bras Epidemiol, 2012; 15(1): 188-97.

15. PEDRAZA DF. Hospitalização por doenças infecciosas, parasitismo e evolução nutricional de crianças atendidas em creches públicas. Ciênc. saúde coletiva, 2017; 22(12).

16. PONTUAL JPS, et al. Estudo etiológico da diarreia em crianças hospitalizadas no Instituto Materno Infantil Prof. Fernando Figueira, IMIP, em Recife, Pernambuco. Rev. Bras. Saude Mater. Infant., 2006; 6(supl.1): s11s17.

17. SABINO LMM, et al. Validation of primer for promoting maternal self-efficacy in preventing childhood diarrhea. Rev. Bras. Enferm. 2018; 71(supl.3).

18. SANTOS AP, et al. Estado nutricional e condições ambientais e de saúde de crianças Pataxó, Minas Gerais, Brasil. Cadernos de Saúde Pública [online]. 2018, 34(6): e00165817.

19. TABORDA RLM, et al. Caracterização de Escherichia coli enteroagregativa entre crianças com diarreia na Amazônia ocidental brasileira. Arq. Gastroenterol. 2018; 55(4).

20. VASCONCELOS MJOB, et al. Factors associated with diarrhea in children under five years old in the state of Pernambuco, according to surveys conducted in 1997 and 2006. Rev. Saúde Pública. 2018; 52. 